\title{
Efficacy of different fibres and flour mixes in South-Asian flatbreads for reducing post-prandial glucose responses in healthy adults
}

\author{
Hanny M. Boers ${ }^{1} \cdot$ Katrina MacAulay $^{2} \cdot$ Peter Murray $^{2} \cdot$ Jack Seijen ten Hoorn $^{1}$ • \\ Anne-Roos Hoogenraad $^{1} \cdot$ Harry P. F. Peters ${ }^{1} \cdot$ Maria A. M. Vente-Spreeuwenberg $^{1}$ • \\ David J. Mela ${ }^{1}$
}

Received: 31 March 2016 / Accepted: 1 June 2016 / Published online: 21 June 2016

(C) The Author(s) 2016. This article is published with open access at Springerlink.com

\begin{abstract}
Purpose Type 2 diabetes (T2DM) is increasing, particularly in South-East Asia. Intake of high-glycaemic foods has been positively associated with T2DM, and feasible routes to reduce the glycaemic response to carbohydraterich staple foods are needed. The research question was whether different fibre and legume flour mixes in flatbreads lower postprandial glucose (PPG) responses.

Methods Using a balanced incomplete block design, we tested the inclusion of guar gum (GG), konjac mannan $(\mathrm{KM})$ and chickpea flour (CPF) in 10 combinations $(2 / 4 / 6 \mathrm{~g}$ GG; $2 / 4 \mathrm{~g} \mathrm{KM} ; 15 \mathrm{~g} \mathrm{CPF}$, and 10 or $15 \mathrm{~g}$ CPF plus 2 or $4 \mathrm{~g} \mathrm{GG}$ ) in $100 \mathrm{~g}$ total of a control commercial high-fibre flatbread flour mix ("atta") on PPG in 38 normal-weight adults. Self-reported appetite was an additional exploratory outcome. An in vitro digestion assay was adapted for flatbreads and assessed for prediction of in vivo PPG.

Results Flatbreads with $6 \mathrm{~g} \mathrm{GG}, 4 \mathrm{~g} \mathrm{KM}$, and $15 \mathrm{~g} \mathrm{CPF}$ plus 2 or 4 g GG reduced PPG $\geq 30 \%(p<0.01)$, while no other combinations differed significantly from the control. A statistical model with four in vitro parameters (rate of digestion, \%RDS, AUC, carbohydrate level) was highly predictive of PPG results (adjusted $R^{2}=0.89$ ). Test products were similar to the control for appetite-related measures.
\end{abstract}

Electronic supplementary material The online version of this article (doi:10.1007/s00394-016-1242-9) contains supplementary material, which is available to authorized users.

Hanny M. Boers

hanny.boers@unilever.com

1 Unilever R\&D Vlaardingen, PO Box 114,

3130 AC Vlaardingen, The Netherlands

2 Unilever Discover R\&D Colworth, Sharnbrook, UK
Conclusions The results confirm the efficacy of specific additions to flatbread flour mixes for reducing PPG and the value of the in vitro model as a predictive tool with these ingredients and product format.

This trial is registered at ClinicalTrials.gov with identifier NCT02671214.

Keywords Atta $\cdot$ Viscous fibre $\cdot$ Glycaemic response $\cdot$ In vitro digestion $\cdot$ Appetite

$\begin{array}{ll}\text { Abbreviations } \\ \text { CPF } & \text { Chickpea flour } \\ C_{\text {max }} & \text { Maximum observed glucose response } \\ \text { GG } & \text { Guar gum } \\ \text { GI } & \text { Glycaemic index } \\ \text { GL } & \text { Glycaemic load } \\ \text { HFF } & \text { High-fibre flour } \\ \text { KM } & \text { Konjac mannan } \\ \text { PPG } & \text { Post-prandial plasma glucose } \\ + \text { iAUC } & \text { Positive incremental area under the curve } \\ \text { RDS } & \text { Rapidly digestible starch } \\ \text { RS } & \text { Resistant starch } \\ \text { SDS } & \text { Slowly digestible starch } \\ \text { tAUC } & \text { Total area under the curve } \\ T_{\max } & \text { Time at which the } C_{\text {max }} \text { is reached } \\ \text { T2DM } & \text { Type } 2 \text { diabetes mellitus }\end{array}$

\section{Introduction}

The global incidence of type 2 diabetes mellitus (T2DM) is increasing at an alarming rate. Developing countries such as India have high and rapidly increasing prevalence of both pre-diabetes and diabetes [1], and consequently, there is considerable public health and consumer interest in 
taking steps to reduce the risk of these conditions developing and progressing. In the early state of T2DM (pre-diabetes), the condition is reversible [2]. Evidence suggests that one of the earliest events in the aetiology of T2DM is dysregulated postprandial blood glucose (PPG) [3]. Targeted reductions in PPG in (pre-)diabetic populations, using the $\alpha$-glucosidase and $\alpha$-amylase inhibitor acarbose, have been shown to result in significant reduction in PPG and improved long-term glycaemic control $[4,5]$, as well as significantly reducing the progression of pre-diabetes to T2DM and cardiovascular events [6]. The benefit of PPG lowering in the prevention of (pre-)diabetes [7] is endorsed by key professional bodies $[8,9]$.

Carbohydrate-rich staple foods are interesting candidates for reducing PPG exposure, because their frequent and consistent use makes them an important contributor to daily glycaemic load [10]. The two most common staples in Southeast Asia are wheat-based flatbreads and rice [11]. Flatbreads are typically prepared at home from a commercially-made whole-wheat flour mix ("atta"). Commercially-viable, efficacious routes to reduce the PPG response to flatbreads are therefore of interest.

Soluble viscous fibres are known to lower PPG, mainly by reducing the rates of gastric emptying and glucose absorption in the intestine [12]. In addition, legume flours, such as chickpea flour (CPF), are known to give a flatter blood glucose response than wheat flours [13]. Previous research has shown that soluble viscous fibres (viz., betaglucan, psyllium and fenugreek) with or without legume flour can lower the PPG of flatbreads [14-16]. While there are no human studies on the combination of guar gum (GG) and CPF, a study in rats showed that a combination of $5 \% \mathrm{CPF}$ and $1 \%$ GG gave a reduction in fasting blood glucose superior to 2 or $3 \% \mathrm{GG}$ alone [17]. As the addition of high levels of viscous fibres may have adverse effects on flatbread mix cost and sensory attributes, routes to achieve efficacy at lower fibre additions are of interest. However, to date there is no clinical study which systematically tested the potential for different soluble fibres with or without legume flour to lower the PPG response to flatbreads. A further question is whether GG could partly be replaced by CPF in flatbreads to achieve reductions in PPG similar to a higher GG level alone. This research was therefore undertaken as a first step in a programme to find efficacious, but also affordable and acceptable routes to lower the PPG response to commercial flatbread mixes.

From the existing literature, additions of konjac mannan (KM) and of GG alone or combined with CPF were prioritized for potential feasibility and efficacy in clinical testing [17-21]. The primary objective of this study was to identify one or more flour compositions that gave a significant difference in the positive incremental area under the 2-h curve $\left(+\mathrm{iAUC}_{2 \mathrm{hr}}\right)$ for plasma glucose after consumption of the test relative to the control product. Exploratory objectives were to estimate the maximum observed glucose response $\left(C_{\max }\right)$, the time at which the $C_{\max }$ was reached $\left(T_{\max }\right)$ and the mean plasma glucose level at $3 \mathrm{~h}$. As soluble viscous fibres and CPFs are also claimed to increase satiety [22, 23], an additional exploratory objective was to assess possible effects on appetiterelated parameters. Finally, an in vitro digestibility assay specifically adapted for flatbreads was developed to assess how well this predicted the observed in vivo results in this product format.

\section{Methods}

\section{Test product and preparation}

The research was based on 12 test products containing $100 \mathrm{~g}$ flour per serving. An existing commercial fibreenriched (high-fibre flour, HFF) commercial mix (market standard atta, Hindustan Unilever Ltd., India) containing whole wheat flour with $5 \mathrm{~g}$ bran per $100 \mathrm{~g}$ was used as the control. The 11 products tested against this included a "market standard" product (no added fibres) and 10 experimental products based on the HFF control with the inclusion of 10 or $15 \mathrm{~g} \mathrm{CPF}, 2$ or $4 \mathrm{~g} \mathrm{KM}, 2,4$ or $6 \mathrm{~g}$ GG per $100 \mathrm{~g}$ flour in combinations shown in Table 1. The viscosity of the GG and KM was tested and verified, and these data are also reported in Table 1. All flour mixes were formulated by the research sponsor (Unilever R\&D, Vlaardingen, The Netherlands). For clinical testing, flatbreads were prepared fresh at the test site. For each single test serving, $100 \mathrm{~g}$ flour was kneaded to a soft and uniform consistency with the addition of $\sim 73 \mathrm{ml}$ water and allowed to rest for $30 \mathrm{~min}$ and then divided into 3 equal balls and rolled to $2-3 \mathrm{~mm}$ thickness. More water was added as needed to achieve the desired texture when fibres or legume flour were incorporated (see Table 1). Flatbreads were subsequently baked and kept warm until consumption within 30 min of cooking or used for in vitro analysis.

\section{Human study}

\section{Participants}

Seventy-three apparently healthy volunteers were recruited for screening from an existing database of potential participants in the local area of Leatherhead Food International (Leatherhead, UK), where the study was conducted. For the detailed selection criteria, see Supplemental Table 1 (Online Resource). The study was conducted according to the principles of Good Clinical Practice, the Declaration of Helsinki (2008) and applicable local laws and regulations 
Table 1 Composition of test flatbreads: available carbohydrates, dietary fibre and water

\begin{tabular}{|c|c|c|c|c|}
\hline Flatbreads & Composition $^{\mathrm{a}}$ & Total available carbs (g) & Total dietary fibre (g) (AOAC 2009.01) & Water ( $\%$ weight $)$ \\
\hline HFF (control) & $100 \mathrm{~g}$ high-fibre flour (HFF) & 61 & 11 & 34.5 \\
\hline 1 & $81 \mathrm{~g} \mathrm{HFF}+15 \mathrm{~g} \mathrm{CPF}^{\mathrm{b}}+4 \mathrm{~g} \mathrm{GG}^{\mathrm{c}}$ & 55 & 16 & 37.1 \\
\hline 2 & $83 \mathrm{~g} \mathrm{HFF}+15$ g CPF + 2 g GG & 56 & 14 & 34.6 \\
\hline 3 & $85 \mathrm{~g} \mathrm{HFF}+15 \mathrm{~g} \mathrm{CPF}$ & 57 & 13 & 30.6 \\
\hline 4 & $86 \mathrm{~g} \mathrm{HFF}+10 \mathrm{~g} \mathrm{CPF}+4 \mathrm{~g} \mathrm{GG}$ & 56 & 15 & 36.8 \\
\hline 5 & $88 \mathrm{~g} \mathrm{HFF}+10 \mathrm{~g} \mathrm{CPF}+2 \mathrm{~g} \mathrm{GG}$ & 57 & 14 & 34.5 \\
\hline 6 & $94 \mathrm{~g} \mathrm{HFF}+6 \mathrm{~g} \mathrm{GG}$ & 57 & 16 & 39.7 \\
\hline 7 & $96 \mathrm{~g} \mathrm{HFF}+4 \mathrm{~g} \mathrm{GG}$ & 59 & 14 & 37.2 \\
\hline 8 & 98 g HFF + 2 g GG & 60 & 13 & 36.8 \\
\hline 9 & $96 \mathrm{~g} \mathrm{HFF}+4 \mathrm{~g} \mathrm{KM}^{\mathrm{d}}$ & 59 & 14 & 39.2 \\
\hline 10 & $98 \mathrm{~g} \mathrm{HFF}+2 \mathrm{~g} \mathrm{KM}$ & 60 & 13 & 37.9 \\
\hline 11 & Market standard atta & 64 & 8 & 33.6 \\
\hline
\end{tabular}

${ }^{\text {a }} H F F$ high-fibre flour (control), $C P F$ chickpea flour, $G G$ guar gum, $K M$ konjac mannan

b Chickpea flour (Avent Agro Pvt. Ltd., Delhi, India)

${ }^{c}$ Guar gum (Ace Gum Industries PVT. LTD, Mumbai, India); viscosity cold $1 \%$ in water, measured by a Brookfield RVF viscometer 20-RPM Spindle no. 4, at $30 \mathrm{~min}: 4500 \mathrm{mpa} . \mathrm{s}$, at $2 \mathrm{~h} 5400 \mathrm{CPS}$ and $24 \mathrm{~h}: 5500 \mathrm{mpa} . \mathrm{s}$

${ }^{\mathrm{d}}$ Konjac mannan (Hubei Konson Konjac Gum Co., LTD., Wuhan Hubei, China); viscosity $25{ }^{\circ} \mathrm{C}, 1 \%$, mix round half an hour, measured by model NDJ-1 viscometer, spindle 4\#, 12-RPM. Test after an hour dissolved; >22,000 mpa.s)

concerning studies conducted on human subjects, not testing a medical product or device. Ethical approval for the study was obtained from the East Kent Local Research Committee. Each participant provided written informed consent prior to his/her inclusion in the study.

Experimental design This study used a double-blind, randomized, balanced-order incomplete block design. Randomization to treatment orders was executed using a computer with a random number generator by a second statistician, who was not involved in the study. All persons involved in the study were blinded. All subjects received the control (HFF) and 4 out of the 11 other test products. For this study design, a power calculation indicated that a minimum of 14 subjects per test product would be required to test for the significance of a $30 \%$ reduction in $+\mathrm{iAUC}_{2 \mathrm{hr}}$ (the area of the PPG response lying above the baseline concentration) vs the control product, assuming a standard deviation of $32.7 \mathrm{mmol} / \mathrm{l}$.min (based on previous studies at the test site), at $\alpha=0.20$ and $\beta=0.80$. With this design and 42 subjects in the study, all of the test products would be tested on at least 15 participants ( 8 products tested by 15 subjects, 3 products tested by 16 subjects and all subjects getting the control).

Subjects attended the initial screening day followed by 5 test days, at least 1 week apart. They were instructed to minimize changes in their diet and activity during the test period. On the day prior to each test day, each subject was instructed to refrain from physical activity and alcohol consumption and to consume their same evening meal. All participants fasted overnight (from $20.00 \mathrm{~h}$ until consumption of the test product), but were allowed to drink water ad libitum. At time $=0 \mathrm{~min}$ on each test day, subjects consumed three freshly made flatbreads ( $100 \mathrm{~g}$ flour total) with $250 \mathrm{ml}$ water as breakfast and completed this within a 15-min period at every visit at the same time and day of the week. They were allowed to drink up to $150 \mathrm{ml}$ water every subsequent hour, to be consumed after finger pricks and self-reported appetite ratings. The volume of water consumed was registered.

Blood collection and glucose measurements Capillary blood was collected by finger prick into lithium heparin and sodium fluoride tubes for plasma glucose analysis. Three basal samples were collected at $-15 \mathrm{~min}$ and then at 15 , 30, 45, 60, 90, 120 and $180 \mathrm{~min}$ after the test meals. All samples were centrifuged (3000 rpm for $10 \mathrm{~min}$ at $4{ }^{\circ} \mathrm{C}$ ) prior to immediate analysis or storage at $-20{ }^{\circ} \mathrm{C}$. Plasma glucose concentrations were measured on a YSI 2300 STAT Plus $^{\mathrm{TM}}$ Glucose and Lactate Analyzer (YSI Life Sciences).

Measurement of appetite Self-ratings of appetite feelings ("how hungry are you", "how full are you" and "how strong is your desire to eat a meal") were made at baseline (preconsumption) and 15, 30, 60 and 120 min post-prandially. These were scored by means of a mark on a 60 -mm Electronic Visual Analogue Scale (EVAS) [24] on a pocket PC (iPAQ), anchored at the low and high end with "not at all" and "extremely" [25]. 


\section{In vitro determination of starch digestibility}

Starch digestibility in vitro was assessed by an adaptation of the Englyst method [26, 27] which has been demonstrated to show good correlation between PPG responses and in vitro starch digestibility in terms of rapidly digestible starch (RDS), slowly digestible starch (SDS) and resistant starch (RS) for a wide range of products [28]. The method was modified with the methods described by Sopade [29] and Van Kempen [30] to provide a glucose release profile describing how much glucose is released per unit of time. Briefly, sliced pieces of chapatti $(500 \mathrm{mg})$ were mixed for $30 \mathrm{~s}$ with an $\alpha$-amylase solution $(1 \mathrm{ml}, 300$ U Sigma 10080) to simulate starch digestion in the mouth. Gastric digestion was simulated by 30 -min incubation at $37{ }^{\circ} \mathrm{C}$ in pepsin solution $(5 \mathrm{ml}, 16 \mathrm{kU}$ Sigma P77160 in $0.05 \mathrm{M} \mathrm{HCl}$ ). After neutralization with $\mathrm{NaOH}$, intestinal digestion was simulated by 4 -h incubation at $37{ }^{\circ} \mathrm{C}$ in pancreatic solution $(30 \mathrm{ml}, 56 \mathrm{mg}$ Sigma P1625 + $100 \mathrm{U}$ Sigma A7095 + $1 \mathrm{kU}$ invertase in $0.2 \mathrm{M}$ acetate buffer $\mathrm{pH}$ 6.0). Aliquots $(200 \mu \mathrm{L})$ from this phase were collected into ethanol at $0,20,60,120,180$ and $240 \mathrm{~min}$, to stop further enzyme activity, and analysed for glucose (Sigma Glucose assay kit GAGO20). The average $(n=2)$ glucose data were fitted with the Chapman-Richards model to give the rate of digestion $(k)$ and the $\mathrm{AUC}_{120}$ using the trapezoidal model (See Online Resource for further explanation).

Statistical methods The primary outcome variable was plasma glucose $+\mathrm{iAUC}_{2 \mathrm{hr}}$. This was calculated using the trapezoidal rule, and linear interpolation was used to establish the time of crossing between time points where the PPG crossed the baseline value. Statistical comparisons were only made between the control and other test products using a mixed model analysis of variance, with subject as a random effect and product as a fixed effect. Baseline (fasting score) for each product was included as a covariate, as was the average baseline per subject over all products, the latter to avoid bias in the product estimates due to the mixed model. Gender, body weight and the order of product testing were all included as covariates. Dunnett's test was used to adjust for the multiple comparisons using an overall significance level of 0.20. All analyses were performed with SAS version 9.2 (SAS Institute, Cary, NC, USA). Exploratory variables included the maximum postmeal plasma glucose concentration $\left(C_{\max }\right)$, time when this was reached $\left(T_{\max }\right)$, mean plasma glucose at $3 \mathrm{~h}$ and self-reported scores on the 3 appetite-related measures. The AUC for appetite ratings scales was calculated using the trapezoidal rule and expressed as the original scale units by dividing by the length of time measured. There were no pre-planned statistical analyses of exploratory measures, and therefore, only descriptive statistics are presented for these. The relationship between in vitro and in vivo measures was analysed with a regression model. Initial correlations and scatter plots for each of these variables with $+\mathrm{iAUC}$ showed that a linear model was unlikely to provide good prediction, so a quadratic model was used.

\section{Results}

\section{Subject baseline characteristics}

From the initial 73 subjects screened for the study, 27 were excluded and 38 subjects completed the study (see Fig. 1), leaving it slightly below the planned power for most test products (9-14 subjects per product). The baseline characteristics of participants are shown in Table 2 (and separately by gender in the Online Resource information supplemental Table 2).

\section{Postprandial plasma glucose concentrations}

Fasting plasma glucose values were similar within test product groups and also within subjects on different test days (data not shown). The observed PPG response patterns for addition of GG, KM and CPF or combinations of $\mathrm{CPF}+\mathrm{GG}$ are shown in Fig. 2a-d. Data for per cent differences in plasma glucose $+\mathrm{iAUC}_{2 \mathrm{hr}}$ vs control are shown in Fig. 3, and the absolute values are given in Table 3. Postprandial plasma glucose $+\mathrm{iAUC}_{2 \mathrm{hr}}$ was statistically significantly reduced from the control HFF in 4 test products: $15 \mathrm{~g} \mathrm{CPF}+4 \mathrm{~g} \mathrm{GG}, 15 \mathrm{~g} \mathrm{CPF}+2 \mathrm{~g} \mathrm{GG}, 6 \mathrm{~g} \mathrm{GG}$ and $4 \mathrm{~g} \mathrm{KM}$ (Table 3; Fig. 2). The data show a general doseresponse reduction in $+\mathrm{iAUC}_{2 \mathrm{hr}}$ with 2 and $4 \mathrm{~g} \mathrm{KM}$ and 2,4 and $6 \mathrm{~g}$ GG relative to control, with the addition of $10 \mathrm{~g} \mathrm{CPF}$ to 2 and $4 \mathrm{~g} \mathrm{GG}$ having little further effect. While addition of $15 \mathrm{~g} \mathrm{CPF}$ alone led to a non-significant increase in PPG and the use of $2 \mathrm{~g} \mathrm{GG}$ and $4 \mathrm{~g} \mathrm{GG}$ non-significantly decreased PPG, the combination of $15 \mathrm{~g} \mathrm{CPF}$ and 2 or $4 \mathrm{~g}$ GG led to marked and significant reductions in glucose $+\mathrm{iAUC}_{2 \mathrm{~h}}$, exceeding a $30 \%$ reduction (Fig. 3 ).

\section{Exploratory outcomes}

$C_{\max }, T_{\max }$ and 3-h plasma glucose data are shown in Table 3. $C_{\max }$ data were largely consistent with the +iAUC data, while $T_{\max }$ was in general little different from the control. Mean plasma glucose at $3 \mathrm{~h}$ for most treatments was mildly raised relative to the control. Appetite data were similar for all test products and suggest no consistent effects relative to the control (See Supplemental Fig. 2a-c (Online Resource)). 
Fig. 1 Flow diagram of participants throughout the study

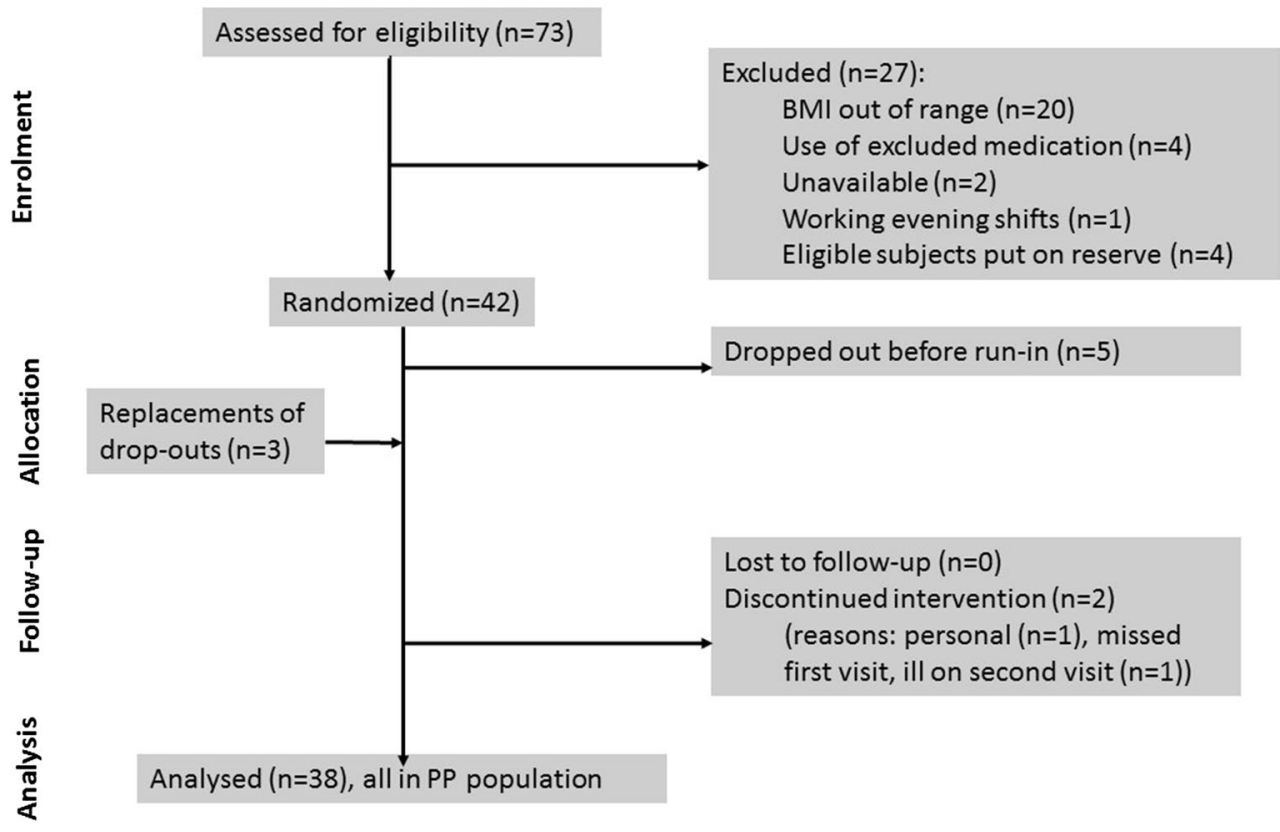

Table 2 Subject baseline demographic characteristics, mean \pm standard deviation

\begin{tabular}{ll}
\hline & $\begin{array}{l}\text { Subject baseline demographic } \\
\text { characteristics (mean } \pm \mathrm{SD})\end{array}$ \\
\hline Age (year) & $37 \pm 9$ \\
Gender (male/female) & $3 / 35$ \\
Height $(\mathrm{m})$ & $1.67 \pm 0.06$ \\
Body weight $(\mathrm{kg})$ & $64.1 \pm 8.7$ \\
BMI $\left(\mathrm{kg} / \mathrm{m}^{2}\right)$ & $22.8 \pm 1.6$ \\
Fasting plasma glucose $(\mathrm{mmol} / \mathrm{l})$ & $5.1 \pm 0.4$ \\
\hline
\end{tabular}

\section{Adverse events}

There were 5 adverse events that possibly could be considered related to the study procedures: 2 times nausea with vomiting, 2 times nausea alone and once with flatulence. Nausea occurred only in conjunction with GG. The participants reporting adverse events were excluded from the statistical analysis.

\section{In vitro measures of starch digestibility}

The separate measures alone from the in vitro assay, such as RDS, SDS, RS, $k$ and AUC, individually had inconsistent relationships with the dose and types of added fibres and likely to be poor predictors for the in vivo +iAUC. A model based on just the Englyst [26, 27] parameters (RDS and RS) also had a poor predictive value (see Online Resource). In contrast, a statistical model comprised of the in vitro parameters $k$ (for rate of digestion), \%RDS, AUC in vitro (=AUC for $120 \mathrm{~min}$ ) and $\mathrm{CHO}$ (=carbohydrate level) was highly predictive of the observed clinical PPG results $\left(R^{2}=0.97\right.$ and adjusted $\left.R^{2}=0.89\right)$ (see Fig. 4). The resulting model was:

$$
\begin{aligned}
+\mathrm{iAUC}= & 31,417+334.6 * \mathrm{CHO}-9729 * k \\
& -4.739 * \mathrm{AUC} \_ \text {in vitro }-32.03 * \mathrm{RDS} \\
& +18.38 * \mathrm{CHO} * k * 1.183 * k * \mathrm{AUC} \_ \text {in vitro } \\
& -3.542 * \mathrm{CHO}^{2}-132.2 * k 2
\end{aligned}
$$

where $k=$ rate of digestion from Chapman-Richards model; AUC in vitro = AUC for $120 \mathrm{~min}$; $\mathrm{CHO}=$ carbohydrates content of flour mix; $\mathrm{RDS}=$ rapidly digestible starch [see Supplemental Table 5 (Online Resource)].

\section{Discussion}

This research demonstrates that several flatbread flour mix (atta) formulations incorporating GG, KM and CPF significantly lower PPG levels relative to a commercial product with added bran fibre. These findings build on previous reports demonstrating that incorporation of viscous dietary fibres and/or legume flours into other staple flatbread foods from India (chapatti, naan, rotis) can lower the PPG response after a meal [14-16]. A novel result is the demonstrated efficacy of $\mathrm{KM}$ in this format and the combination of CPF with low levels of GG in human subjects, as efficacy of this combination previously had been shown only in animals [17]. This suggests the potential for affordable, efficacious formulations with lower levels of GG, which may mitigate its adverse sensory impact. 

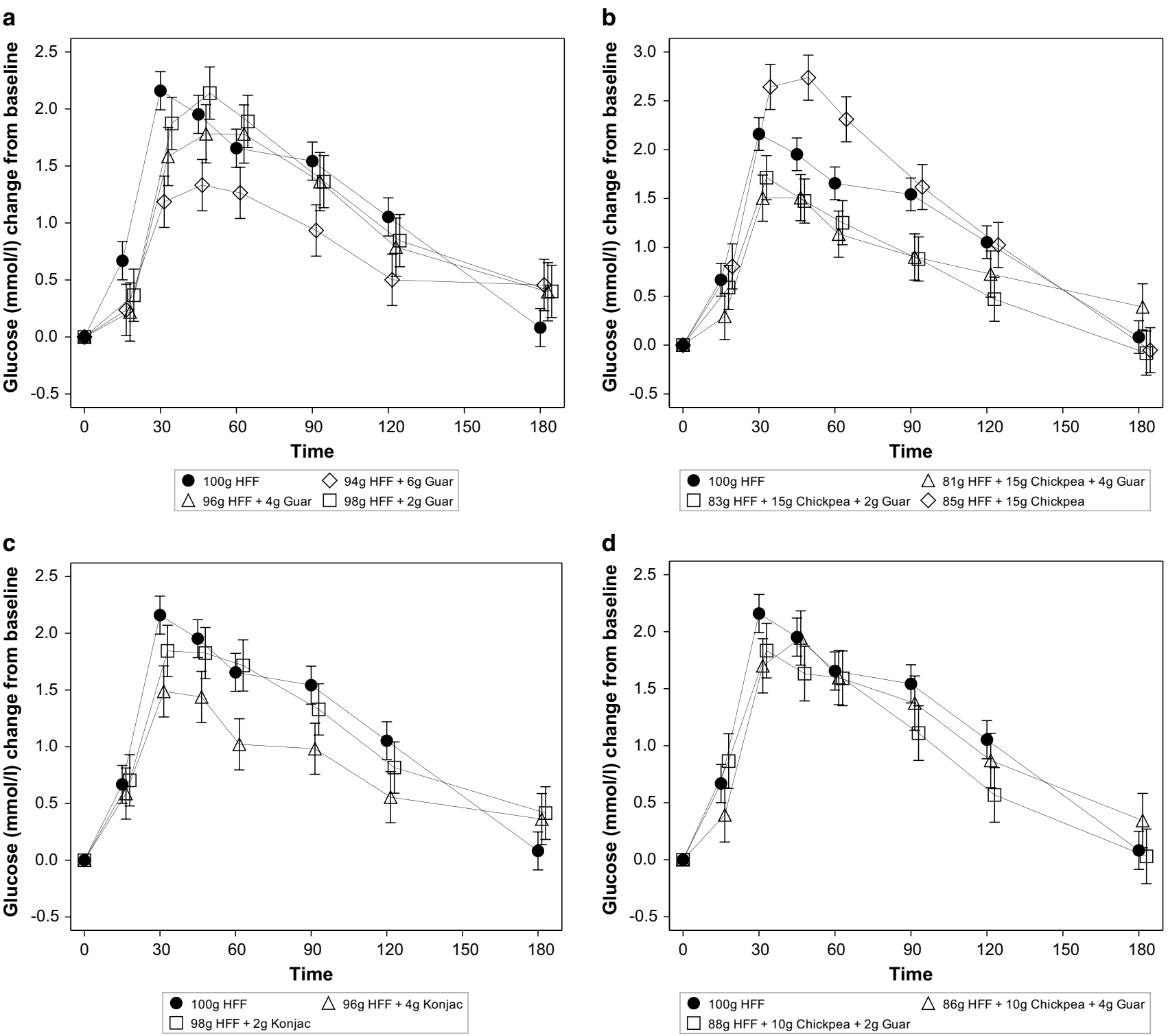

Fig. 2 Effect of flatbreads consumption with different amounts of viscous fibres and legume flour on postprandial glucose (mean $\pm \mathrm{SEM})(H F F$ high-fibre flatbread control). a Effect of flatbread consumption with different amounts of guar gum on postprandial plasma glucose (mean \pm SEM) ( HFF high-fibre flatbread control). b Effect of flatbread consumption with different amounts of chickpea flour $(15 \mathrm{~g})$ without or with guar gum on postprandial

We chose to measure the area under the curve and particularly the $+\mathrm{iAUC}$, because this has frequently been used in human intervention studies (e.g. testing variation in glycaemic index (GI)) [31]. In addition, the +iAUC describes the glycaemic response to foods more accurately [32] than the total AUC. The $C_{\max }$ data are also largely consistent with the +iAUC, which is to be expected, and a reduced $C_{\max }$ is also seen as clinically beneficial [33]. The $C_{\max }$ data further suggest that the lowering of the iAUC is not so much due to a higher insulin response [34], but more likely

plasma glucose (mean \pm SEM) (HFF high-fibre flatbread control). c Effect of flatbread consumption with different amounts of konjac mannan on postprandial plasma glucose (mean \pm SEM) (HFF highfibre flatbread control). d Effect of flatbread consumption with chickpea flour $(10 \mathrm{~g})$ and different amounts of guar gum on postprandial plasma glucose (mean \pm SEM) ( $H F F$ high-fibre flatbread control)

due to other processes, e.g. rate of uptake. In contrast, $T_{\max }$ data are similar amongst treatments. The plasma glucose level at three hours (see Table 3) was mildly increased for the flatbreads containing viscous fibres compared to the control, which may reflect a slower digestion of starch and thus continued absorption of glucose from the intestine, as well as a lower insulin response and thus slower return of glucose to fasting levels. Although that effect is small, it would contribute to reduced glycaemic variability, which is seen as a risk factor for diabetes [3]. 
Fig. 3 Percentage change (mean $\pm \mathrm{SEM}$ ) in PPG

$\left(+\mathrm{iAUC}_{2 \mathrm{hr}}\right)$ of flatbreads with different amounts of viscous fibres and/or legume flour and $p$ value for change relative to the control flatbread without additions of viscous fibres or legume flour

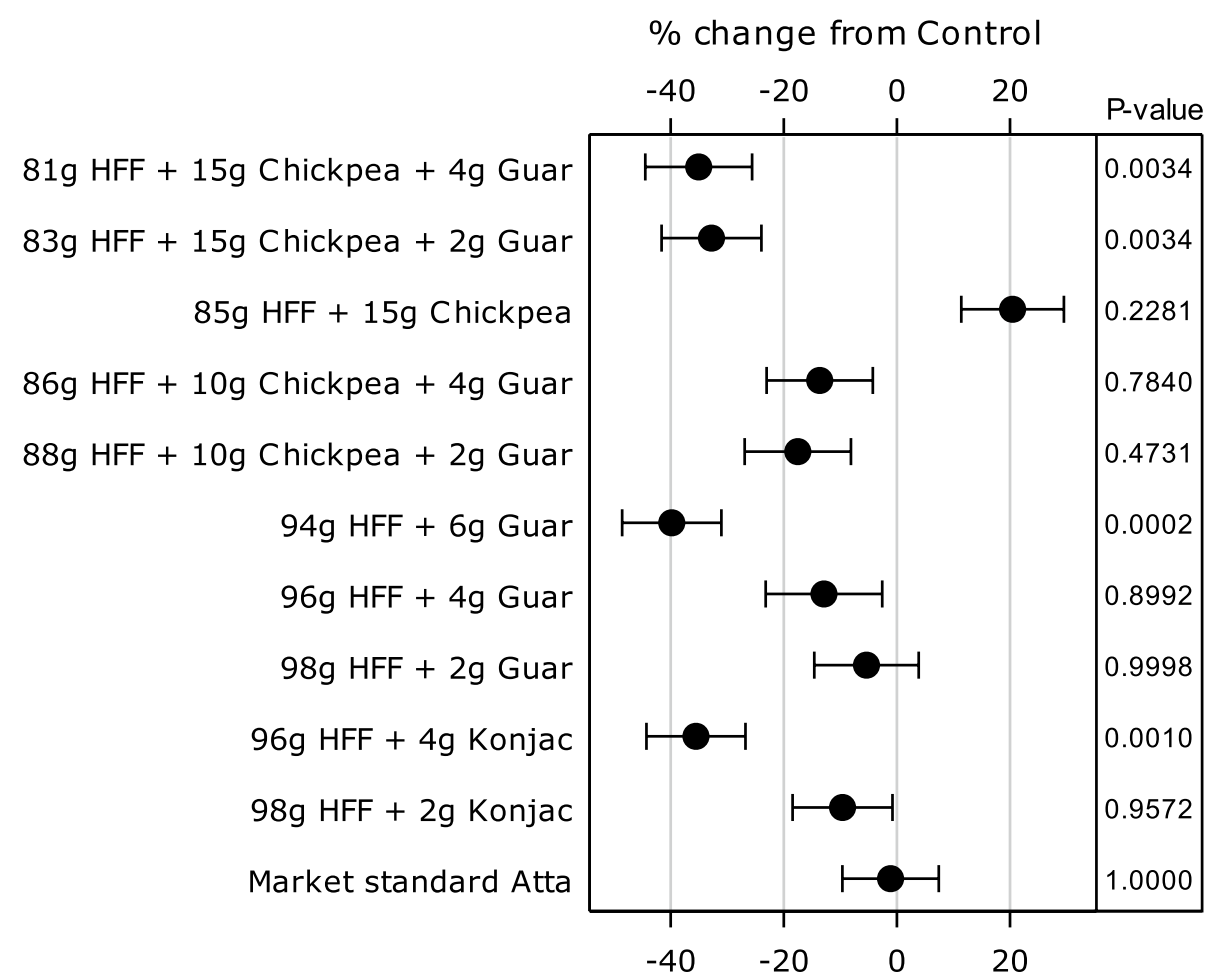

Although a general dose-response effect for the addition of 2, 4 and $6 \mathrm{~g}$ of GG alone was observed in this study, the effect of $6 \mathrm{~g}$ GG was much larger and statistically significant compared to the control product. Other studies have

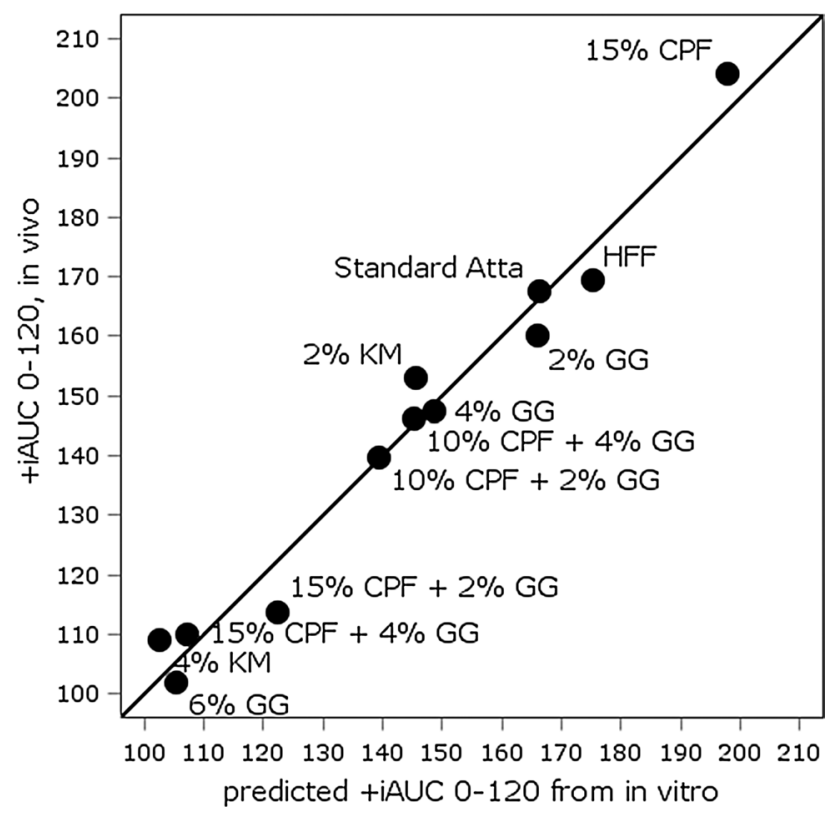

Fig. 4 Observed in vivo response (+iAUC) for postprandial plasma glucose response versus the value predicted based on in vitro data (statistical model as described in text and Online Resource). $H F F$ high-fibre flour (control), $C P F$ chickpea flour, $G G$ guar gum and $K M$ konjac mannan shown the efficacy of GG for lowering PPG [19, 20, 35, 36]; however, a general threshold and dose-response level cannot be determined from those studies, partly because different sources of GG (e.g. different molecular weights and chain lengths) were used and in different food formats. There are, however, a number of studies testing GG incorporated into bread, and these gave results broadly similar to the GG outcomes here. Wolever et al. [36] showed that $5 \mathrm{~g} \mathrm{GG}$ in bread (10\% of the carbohydrate component) lowered the +iAUC by $42 \%$, while Gatenby et al. [35] observed that $7.6 \mathrm{~g}$ GG with different molecular weights reduced the $+\mathrm{iAUC}$ by $23-27 \%$. Those results were also reflected in data from Wolf et al. [20], who showed that $5 \mathrm{~g}$ GG in a drink (containing $25 \mathrm{~g}$ maltodextrin), consumed together with bread, lowered the +iAUC by $24 \%$. Lastly, addition of medium-weight GG (3.8 g, $9 \mathrm{~g}$ and $14.8 \mathrm{~g})$ to breads containing high-amylose whole grain corn flour produced a dose-related reduction in glycaemic response [19].

The potential mechanisms of action of viscous soluble fibres such as GG and KM on PPG can be very diverse, ranging from reducing the rate of gastric emptying to reducing starch digestion and absorption in the intestine resulting in a lower PPG and insulin response [12]. The viscosity generated by plant gums is a function of the concentration of the dissolved gum and its molecular weight (MW) [37]. In this study, we used native GG, but commercially this can be hydrolysed into GG with lower MWs and correspondingly lower viscosity in the mouth as well as gastrointestinal tract, often resulting in a decreased effect 


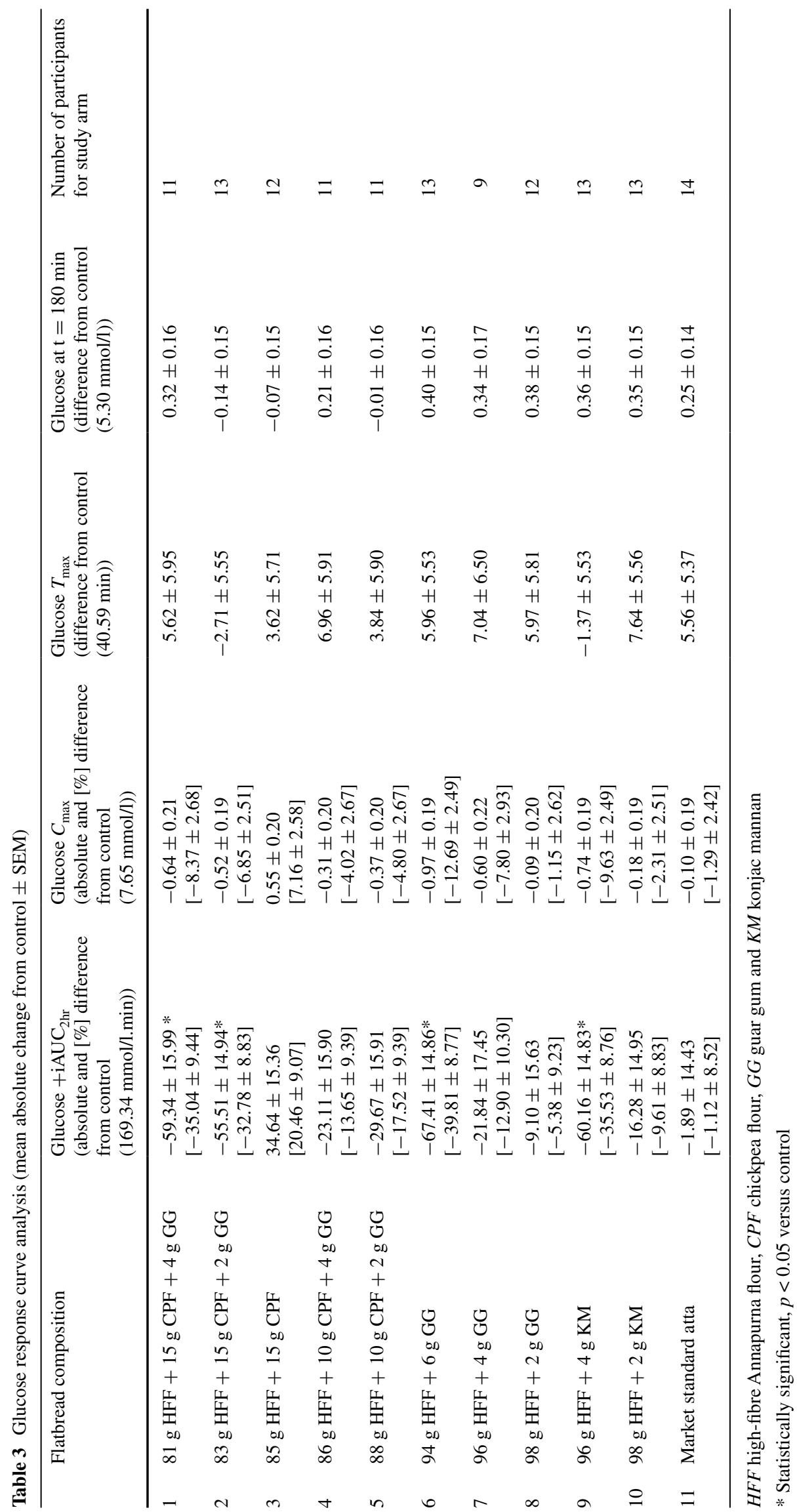


on PPG [34, 35, 38, 39]. There are also indications that some viscous fibres (e.g. GG) can directly inhibit digestive enzymes [40]. On the product level, viscous fibres can also alter the rheological and/or microstructural properties of the food, resulting in reduced ability of the starch to gelatinize during cooking [41]. Viscous fibres are believed to compete with starch for water in food formats resulting in decreased gelatinization [42]. In addition, GG galactomannans may form a "barrier" around starch granules, making them resistant to enzymatic hydrolysis [43].

$\mathrm{KM}$, another viscous fibre, was also introduced into this study to test the influence of viscosity on PPG. Chearskul et al. [44] evaluated the effect of $1 \mathrm{~g} \mathrm{KM}$ in a capsule given $30 \mathrm{~min}$ before an oral glucose tolerance test in 20 diabetic subjects. At $60 \mathrm{~min}$, the blood glucose concentration with KM was $7 \%$ higher than in the control group, while at 120 min there was no difference between the two groups. The lack of any apparent beneficial effect in that study can possibly be explained by the matrix. The capsules, although taken with water, may not fully develop their viscosity under gastrointestinal conditions due to the time required for the fibre to fully hydrate. Doi [18] showed that $3.9 \mathrm{~g}$ $\mathrm{KM}$ mixed into soup decreased the rise in blood glucose at 30 min after consumption by about $30 \%$ versus the control.

In our study, the addition of $4 \mathrm{~g} \mathrm{KM}$ had nearly the same effect as $6 \mathrm{~g} \mathrm{GG}$, and this can likely be attributed to the higher viscosity of KM compared to GG (see footnotes to Table 1). KM is a glucomannan, while GG is a galactomannan. Compared with other native dietary fibres at similar concentrations, glucomannan has the highest viscosity and MW, ranging from 200 to $2000 \mathrm{kDa}$, depending upon the origin, method of processing and storage time [45]. Others have reported a highly significant inverse relationship between the peak blood glucose response and the log viscosity of drinks differing in the amounts of viscous fibre [46]. In the present study, only the highest level of $4 \mathrm{~g} \mathrm{KM}$ had a substantial and statistically significant effect and not the $2 \mathrm{~g}$ addition, which was comparable in viscosity to the $4 \mathrm{~g}$ guar gum. A possible explanation is that the $\mathrm{KM}$ may not have been fully viscosified under gastrointestinal conditions, due to the lower solubility of KM in the solid food matrix.

In addition to increasing viscosity, replacement of wheat flour by legume flour could also have a beneficial effect on PPG. There is some evidence that CPF can lower the PPG due to its higher content of resistant starch [47] and high concentration of slowly digestible starch [48]. Zafar et al. [21] found that supplementation of whole wheat bread with $35 \%$ (but not $25 \%$ ) CPF significantly reduced the glycaemic response. This result was also corroborated by Johnson et al. [49] in white bread. In contrast to the fact that $15 \mathrm{~g}$ CPF in combination with 2 and $4 \mathrm{~g}$ of GG markedly and significantly reduced PPG, we found that the inclusion of
$15 \mathrm{~g} \mathrm{CPF}$ alone in the flatbreads (though not significantly) increased PPG. The reason for the latter could be that fine grinding of legumes (as is the case for CPF) disrupts the cell structure and renders starch more readily accessible for digestion [50].

We found little apparent effect of the tested additions on self-reported appetite ratings. Other research suggests that changes in blood glucose per se may have limited effects on appetite [51, 52]. Clark and Slavin [53] furthermore described in a systematic review that most fibres do not reduce appetite in acute study designs. Nevertheless, there are a number of reports of enhanced satiety effects associated with the addition of legumes or specific fibres to foods and beverages [22, 23]. A systematic review of randomized controlled trials showed that GG (mean fibre dose: $10.7 \mathrm{~g}$ ) led to significantly reduced appetite ratings in half of the observed comparisons in the literature [23]. Studies with preloads of KM before a meal did not produce significant effects on hunger, fullness or appetite scores [54, 55]. Addition of 25 or $35 \% \mathrm{CPF}$ to whole wheat bread also did not decrease appetite scores [21]. While a recent metaanalysis of acute feeding trials reported that dietary pulses (beans, peas, chickpeas and lentils) produced on average a $31 \%$ greater satiety iAUC [22], the doses used varied substantially, ranging from 7.6 to $311 \mathrm{~g}$ (median, $160 \mathrm{~g}$ ).

While this study used Caucasian subjects, the results are likely to also be applicable (and even more relevant) to other populations, such as those in Asia. Asian populations in general have a higher PPG response than Caucasians [56], and lowering GI is more relevant for people with poor metabolic control [57].

The in vitro digestibility method used here showed a very high correlation with in vivo PPG results. Several other studies have found a good correlation between the in vitro digestion of breads and the in vivo glycaemic response [16, 58-60]. Our method is based on that of Englyst [26, 27], but modified to reflect more realistic physiological conditions. The modification by Sopade [29] was introduced to simulate oral digestion by mixing the food with pancreatic alpha-amylase for $30 \mathrm{~s}$. Another possible improvement in the Englyst method is the optimization of the intestinal $\mathrm{pH}$ and its amount for optimal functioning of the enzymes (see Online Resource). A final modification of the Englyst method was the extension of the number of data points to determine the rate of digestion of slowly digestible starches. By doing this, the in vitro starch digestibility curve provides more information than would be possible from using data only at 20 and $120 \mathrm{~min}$. Single individual parameters measured or derived from in vitro digestion showed rather inconsistent relationships to the dose and types of added fibres or CPF. However, in vitro glucose release from starch could be modelled effectively with a modification of the Chapman-Richards 
model (see Online Resource) described by van Van Kempen [30]. With this model, the rate of starch digestibility (k) can be estimated, and together with \%RDS, AUC 120 and the carbohydrate level in a regression model there was a very high correlation with in vivo plasma glucose responses.

There are some limitations of the study that may affect direct extrapolation to other situations. The study population has a very high proportion of women. However, we did not have any a priori selection criteria or hypotheses relating to gender, and previous research suggests gender is not a significant contributor to between-food variation in glycemic responses [61]. For some treatments, the study was underpowered due to unequal numbers of dropouts across treatment sequences. In addition, specific sources of GG and KM have been used and other types of GG or $\mathrm{KM}$ could possibly influence the glycaemic response differently. One of the strengths of the study is that it is well controlled as the incomplete block design allows for all the comparisons to be executed within one study period and population.

Taken together, these data demonstrate that flatbread flour mixes supplemented with specific combinations of GG and CPF or higher concentrations of GG of KM alone can produce marked, significant reductions in PPGs (i.e. $\geq 30 \%$ reduction in $+\mathrm{iAUC}$ ) in healthy adults. The results also show that a model using a range of in vitro measured parameters may be a useful predictive tool for in vivo PPG responses to these ingredients in this product format.

\begin{abstract}
Acknowledgements We are grateful to Jeroen Sterken, Anton Porcu and Miranda Slotboom (Unilever Clinicals, Vlaardingen) for facilitating the protocol development and procedures for the clinical study, to Chandrika Mohanan and her team at Unilever R\&D Bangalore for providing the flours and to Leatherhead Food International, Leatherhead, UK, for executing the clinical study. HMB, KM, A-RH, MAMV, PM and DJM designed the research; MAMV and A-RH facilitated execution of the study; PM performed statistical analysis; $\mathrm{JStH}$ executed in vitro digestion model; HMB wrote the manuscript with significant contributions from DJM, KM, PM, JStH and HPFP. HMB and DJM had primary responsibility for final content. All authors read and approved the final manuscript.
\end{abstract}

Source of financial support This research was entirely funded by Unilever.

\section{Compliance with ethical standards}

Conflict of interest All authors are employees of Unilever, which manufactures and markets consumer food products, including the flour used for the flatbreads in this study.

Ethical standards This human study has been approved by the East Kent Local Research Committee (UK), and therefore, the study was conducted according to the principles of Good Clinical Practice, the Declaration of Helsinki (2008) and applicable local laws and regulations concerning studies conducted on human subjects, not testing a medical product or device. Each participant provided written informed consent prior to his/her inclusion in the study.

Open Access This article is distributed under the terms of the Creative Commons Attribution 4.0 International License (http://creativecommons.org/licenses/by/4.0/), which permits unrestricted use, distribution, and reproduction in any medium, provided you give appropriate credit to the original author(s) and the source, provide a link to the Creative Commons license, and indicate if changes were made.

\section{References}

1. Kaveeshwar SA, Cornwall J (2014) The current state of diabetes mellitus in India. Australas Med J 7:45-48

2. Tabak AG, Herder C, Rathmann W, Brunner EJ, Kavimaki M (2012) Prediabetes: a high-risk state for diabetes development. Lancet 379:2279-2290

3. Monnier L, Colette C, Dunseath GJ, Owens DR (2007) The loss of postprandial glycemic control precedes stepwise deterioration of fasting with worsening diabetes. Diabetes Care 30:263-269

4. Schnell O, Mertes G, Standl E (2007) Acarbose and metabolic control in patients with type 2 diabetes with newly initiated insulin therapy. Diabetes Obes Metab 9:853-858

5. Van De Laar FA, Lucassen PLBJ, Akkermans RP, Van De Lisdonk EH, De Grauw WJC (2006) Alpha-glucosidase inhibitors for people with impaired glucose tolerance or impaired fasting blood glucose. Cochrane Database Syst Rev

6. Chiasson JL, Josse RG, Gomis R, Hanefeld M, Karasik A, Laakso M (2002) Acarbose for prevention of type 2 diabetes mellitus: the STOP-NIDDM randomised trial. Lancet 359:2072-2077

7. Tuomilehto J, Lindstrom J, Eriksson JG, Valle TT, Hamalainen $H$, Ianne-Parikka $P$, Keinanen-Kiukaanniemi S, Laakso $M$, Louheranta A, Rastas M, Salminen V, Uusitupa M (2001) Prevention of type 2 diabetes mellitus by changes in lifestyle among subjects with impaired glucose tolerance. N Engl J Med 344:1343-1350

8. International Diabetes Federation: Guideline for Management of Postmeal Glucose (2007)

9. International Diabetes Federation: Guideline for Management of Postmeal Glucose (2011)

10. Lafiandra D, Riccardi G, Shewry PR (2014) Improving cereal grain carbohydrates for diet and health. J Cereal Sci 59:312-326

11. Henry CJK, Kaur B (2014) Diet-based management and treatment of diabetes. In: Mohan V, Unnikrishnan R (eds) World clinics-Diabetologia-Type 2 diabetes mellitus. Jaypee Brothers Medical Publishers (P) Ltd, New Delhi, pp 1-19

12. Jenkins DJA, Kendall CWC, Axelsen M, Augustin LSA, Vuksan V (2000) Viscous and nonviscous fibres, nonabsorbable and low glycaemic index carbohydrates, blood lipids and coronary heart disease. Curr Opin Lipidol 11:49-56

13. Goni I, Valentin-Gamazo C (2003) Chickpea flour ingredient slows glycemic response to pasta in healthy volunteers. Food Chem 81:511-515

14. Khawaja KI, Fatima A, Mian SA, Mumtaz U, Moazzum A, Ghias M, Masud F (2012) Glycaemic, insulin and ghrelin responses to traditional South Asian flatbreads in diabetic and healthy subjects. Br J Nutr 108:1810-1817

15. Radhika G, Sumathi C, Ganesan A, Sudha V, Henry CJK (2010) Glycaemic index of Indian flatbreads (rotis) prepared using whole wheat flour and atta mix-added whole wheat flour. Br J Nutr 103:1642-1647 
16. Thondre PS, Henry CJK (2009) High-molecular-weight barley beta-glucan in chapatis (unleavened Indian flatbread) lowers glycemic index. Nutr Res 29:480-486

17. Butt MS, Shahzadi N, Suleria HAR, Sultan T, Chohan MI (2011) Effect of dietary fiber in lowering serum glucose and body weight in sprague dawley rats. Functional Foods in Health and Disease 8:261-278

18. Doi K (1995) Effect of konjac fibre (glucomannan) on glucose and lipids. Eur J Clin Nutr 49:S190-S197

19. Ekstrom LM, Bjorck IM, Ostman EM (2013) On the possibility to affect the course of glycaemia, insulinaemia, and perceived hunger/satiety to bread meals in healthy volunteers. Food Funct 4:522-529

20. Wolf BW, Wolever TMS, Lai CS, Bolognesi C, Radmard R, Maharry KS, Garleb KA, Hertzler SR, Firkins JL (2003) Effects of a beverage containing an enzymatically induced-viscosity dietary fiber, with or without fructose, on the postprandial glycemic response to a high glycemic index food in humans. Eur $\mathrm{J}$ Clin Nutr 57:1120-1127

21. Zafar TA, Al-Hassawi F, Al-Khulaifi F, Al-Rayyes G, Waslien C, Huffman FG (2015) Organoleptic and glycemic properties of chickpea-wheat composite breads. J Food Sci Technol 52:2256-2263

22. Li SS, Kendall CWC, De Souza RJ, Jayalath VH, Cozma AI, Ha V, Mirrahimi A, Chiavaroli L, Augustin LSA, Blanco Mejia S, Leiter LA, Beyene J, Jenkins DJA, Sievenpiper JL (2014) Dietary pulses, satiety and food intake: a systematic review and meta-analysis of acute feeding trials. Obesity 22:1773-1780

23. Wanders AJ, van den Borne JJGC, De GC, Hulshof T, Jonathan MC, Kristensen M, Mars M, Schols HA, Feskens EJM (2011) Effects of dietary fibre on subjective appetite, energy intake and body weight: a systematic review of randomized controlled trials. Obes Rev 12:724-739

24. Stratton RJ, Stubbs RJ, Hughes D, King N, Blundell JE, Elia M (1998) Comparison of the traditional paper visual analogue scale questionnaire with an Apple Newton electronic appetite rating system (EARS) in free living subjects feeding ad libitum. Eur J Clin Nutr 52:37-74

25. Blundell J, De GC, Hulshof T, Jebb S, Livingstone B, Lluch A, Mela D, Salah S, Schuring E, Van Der Knaap H, Westerterp M (2010) Appetite control: methodological aspects of the evaluation of foods. Obes Rev 11:251-270

26. Englyst HN, Kingman SM, Cummings JH (1992) Classification and measurement of nutritionally important starch fractions. Eur J Clin Nutr 46:S33-S50

27. Englyst HN, Veenstra J, Hudson GJ (1996) Measurement of rapidly available glucose (RAG) in plant foods: A potential in vitro predictor of the glycaemic response. Br J Nutr 75:327-337

28. Englyst KN, Englyst HN, Hudson GJ, Cole TJ, Cummings JH (1999) Rapidly available glucose in foods: An in vitro measurement that reflects the glycemic response. Am J Clin Nutr 69:448-454

29. Sopade PA, Gidley MJ (2009) A rapid in vitro digestibillity assay based on glucometry for investigating kinetics of starch digestion. Starch 61:245-255

30. Van Kempen TATG, Regmi PR, Matte JJ, Zijlstra RT (2010) In vitro starch digestion kinetics, corrected for estimated gastric emptying, predict portal glucose appearance in pigs. J Nutr 140:1227-1233

31. Brouns F, Bjorck I, Frayn KN, Gibbs AL, Lang V, Slama G, Wolever TMS (2005) Glycaemic index methodology. Nutr Res Rev 18:145-171

32. Le Floch JP, Escuyer P, Baudin E, Baudon D, Perlemuter L (1990) Blood glucose area under the curve: methodological aspects. Diabetes Care 13:172-175
33. Abdul-Ghani MA, Lyssenko V, Tuomi T, DeFronzo RA, Groop L (2010) The shape of plasma glucose concentration curve during OGTT predicts future risk of type 2 diabetes. Diabete Metab Res Rev 26:280-286

34. Ellis PR, Dawoud FM, Morris ER (1991) Blood glucose, plasma insulin and sensory responses to guar-containing wheat breads: effects of molecular weight and particle size of guar gum. Br J Nutr 66:363-379

35. Gatenby SJ, Ellis PR, Morgan LM, Judd PA (1996) Effect of partially depolymerized guar gum on acute metabolic variables in patients with non-insulin-dependent diabetes. Diabetes Med 13:358-364

36. Wolever TMS, Jenkins DJA, Nineham R, Alberti KGMM (1979) Guar gum and reduction of post-prandial glycaemia: Effect of incorporation into solid food, liquid food and both. Br J Nutr 41:505-510

37. Wood PJ, Beer MU, Butler G (2000) Evaluation of role of concentration and molecular weight of oat beta-glucan in determining effect of viscosity on plasma glucose and insulin following an oral glucose load. Br J Nutr 84:19-23

38. Dall'Alba V, Silva FM, Antonio JP, Steemburgo T, Royer CP, Almeida JC, Gross JL, Azevedo MJ (2013) Improvement of the metabolic syndrome profile by soluble fibre-guar gum-in patients with type 2 diabetes: a randomised clinical trial. $\mathrm{Br} \mathrm{J}$ Nutr 110:1601-1610

39. Uusitupa M, Siitonen O, Savolainen K, Silvasti M, Penttila I, Parviainen M (1989) Metabolic and nutritional effects of longterm use of guar gum in the treatment of noninsulin-dependent diabetes of poor metabolic control. Am J Clin Nutr 49:345-351

40. Slaughter SL, Ellis PR, Jackson EC, Butterworth PJ (2002) The effect of guar galactomannan and water availability during hydrothermal processing on the hydrolysis of starch catalysed by pancreatic alpha-amylase. Biochim Biophys Acta 1571:55-63

41. Symons LJ, Brennan CS (2004) The influence of (1-3) (1-4)-beta-D-glucan-rich fractions from barley on the physicochemical properties and in vitro reducing sugar release of white wheat breads. J Food Sci 69:C463-C467

42. Tester RF, Sommerville MD (2003) The effects of non-starch polysaccharides on the extent of gelatinisation, swelling and alpha-amylase hydrolysis of maize and wheat starches. Food Hydrocoll 17:41-54

43. Brennan CS, Blake DE, Ellis PR, Schofield JD (1996) Effects of guar galactomannan on wheat bread microstructure and on the in vitro and in vivo digestibility of starch in bread. J Cereal Sci 24:151-160

44. Chearskul S, Sangurai S, Nitiyanant W, Kriengsinyos W, Kooptiwut S, Harindhanavudhi T (2007) Glycemic and lipid responses to glucomannan in Thais with type 2 diabetes mellitus. Med Assoc Thai 90:2150-2157

45. Chua M, Baldwin TC, Hocking TJ, Chan K (2010) Traditional uses and potential health benefits of Amorphophallus konjac K. Koch ex N.E. Br J Ethnopharmacol 128:268-278

46. Wood PJ, Braaten JT, Scott FW, Riedel KD, Wolynetz MS, Collins MW (1994) Effect of dose and modification of viscous properties of oat gum on plasma glucose and insulin following an oral glucose load. Br J Nutr 72:731-743

47. Jukanti AK, Gaur PM, Gowda CLL, Chibbar RN (2012) Nutritional quality and health benefits of chickpea (Cicer arietinum L.): a review. Br J Nutr 108:S11-S26

48. Nestel P, Cehun M, Chronopoulos A (2004) Effects of long-term consumption and single meals of chickpeas on plasma glucose, insulin, and triacylglycerol concentrations. Am J Clin Nutr 79:390-395

49. Johnson SK, Thomas SJ, Hall RS (2005) Palatability and glucose, insulin and satiety responses of chickpea flour and extruded 
chickpea flour bread eaten as part of a breakfast. Eur J Clin Nutr 59:169-176

50. Jarvi AE, Karlstrom BE, Granfeldt YE, Bjorck IME, Vessby BOH, Asp NGL (1995) The influence of food structure on postprandial metabolism in patients with non-insulin-dependent diabetes mellitus. Am J Clin Nutr 61:837-842

51. Aston LM, Stokes CS, Jebb SA (2008) No effect of a diet with a reduced glycaemic index on satiety, energy intake and body weight in overweight and obese women. In J Obes 32:160-165

52. Peters HPF, Ravestein P, Van Der Hijden HTWM, Boers HM, Mela DJ (2011) Effect of carbohydrate digestibility on appetite and its relationship to postprandial blood glucose and insulin levels. Eur J Clin Nutr 65:47-54

53. Clark MJ, Slavin JL (2013) The effect of fiber on satiety and food intake: a systematic review. J Am Coll Nutr 32:200-211

54. Keithley JK, Swanson B, Mikolaitis SL, Demeo M, Zeller JM, Fogg L, Adamji J (2013) Safety and efficacy of glucomannan for weight loss in overweight and moderately obese adults. J Obes. doi:10.1155/2013/610908

55. Vuksan V, Panahi S, Lyon M, Rogovik AL, Jenkins AL, Leiter LA (2009) Viscosity of fiber preloads affects food intake in adolescents. Nutr Metab Cardiovasc Dis 19:498-503
56. Dickinson S, Colagiuri S, Faramus E, Petocz P, Brand-Miller JC (2002) Postprandial hyperglycemia and insulin sensitivity differ among lean young adults of different ethnicities. J Nutr 132:2574-2579

57. Livesey G, Taylor R, Hulshof T, Howlett J (2008) Glycemic response and health - a systematic review and meta-analysis: Relations between dietary glycemic properties and health outcomes. Am J Clin Nutr 87:258S-268S

58. Ferrer-Mairal A, Penalva-Lapuente C, Iglesia I, Urtasun L, De Miguel-Etayo P, Remon S, Cortes E, Moreno LA (2012) In vitro and in vivo assessment of the glycemic index of bakery products: influence of the reformulation of ingredients. Eur J Nutr 51:947-954

59. Lau E, Soong YY, Zhou W, Henry J (2015) Can bread processing conditions alter glycaemic response? Food Chem 173:250-256

60. Thondre PS, Monro JA, Mishra S, Henry CJK (2010) High molecular weight barley beta-glucan decreases particle breakdown in chapattis (Indian flat breads) during in vitro digestion. Food Res Int 43:1476-1481

61. Wolever TMS, Vorster HH, Bjorck I, Brand-Miller JC, Brighenti F, Mann JI, Ramdath DD, Granfeldt Y, Holt S, Perry TL, Venter C, Wu X (2003) Determination of the glycemic index of foods: interlaboratory study. Eur J Clin Nutr 57:475-482 